Materials Science and Engineering A 442 (2006) 297-301.

\title{
Elasticity study on collective motion in metallic glasses
}

\author{
T. Takahashi, H. Tanimoto and H. Mizubayashi* \\ Institute of Materials Science, University of Tsukuba, Tsukuba, Ibaraki 305-8573, Japan
}

\begin{abstract}
The frequency ( $f$ ) dependence, $E\left(\varepsilon_{t 0}, f\right)$, and the strain amplitude $\left(\varepsilon_{t}\right)$ dependence, $E\left(\varepsilon_{t}, f_{0}\right)$, of the dynamic Young's modulus in $a-\mathrm{Cu}_{50} \mathrm{Ti}_{50}$ (MMG), $a-\mathrm{Zr}_{50} \mathrm{Cu}_{50}$ (MMG) and $a-\mathrm{Zr}_{55} \mathrm{Cu}_{30} \mathrm{Al}_{10} \mathrm{Ni}_{5}(\mathrm{BMG})$ were investigated at room temperature by means of the vibrating reed method in the frequency range between $10^{1} \mathrm{~Hz}$ and $10^{4} \mathrm{~Hz}$, where $\varepsilon_{t 0} \sim 10^{-6}, f_{0} \sim 10^{2} \mathrm{~Hz}$ and MMG and BMG are abbreviations of marginal and bulk metallic glasses, respectively. The effect of passing direct-current (PEC) on $E\left(\varepsilon_{t}, f_{0}\right)$ was also investigate. The strong decrease in $E\left(\varepsilon_{t 0}, f\right)$ between $10^{1} \mathrm{~Hz}$ and $10^{4} \mathrm{~Hz}$, the strong increase in $E\left(\varepsilon_{t}, f_{0}\right)$ with increasing $\varepsilon_{t}$ below $0.2 \%$ and the net increase in $E\left(\varepsilon_{t}, f_{0}\right)$ under PEC with the current density of $10^{7} \mathrm{~A} / \mathrm{m}^{2}$ were commonly found, indicating that the resonant collective motions of many atoms were excited in metallic glasses. For $a-\mathrm{Zr}_{50} \mathrm{Cu}_{50}$ and $a-\mathrm{Zr}_{55} \mathrm{Cu}_{30} \mathrm{Al}_{10} \mathrm{Ni}_{5}$, the effective charge, $Z^{*}$, for the effects of PEC was found to be $10^{5}$ and showed decrease with increasing $f$. The magnitudes of all the changes were similar among the metallic glasses, indicating that the correlation between the collective motions and the free volume contained in metallic glasses is not too strong. The underlying mechanism was discussed.
\end{abstract}

Keywords; metallic glasses, resonant collective motion, density fluctuation, free volume *Corresponding author. E-mail address: mizubayashi@ims.tsukuba.ac.jp

\section{Introduction}

Finding of acceleration of thermal crystallization in metallic glasses by an electric current $[1,2]$ was the beginning of observation for various phenomena associated with collective motions of many atoms in metallic glasses. The reported characteristic phenomena are an increase in the dynamic Young's modulus at low-temperatures [3] and a decrease in the crystallization temperature, $T_{X}$, by 10 to $20 \mathrm{~K}$ at elevated temperatures [4] by passing an electric direct-current (PEC) of $10^{7} \mathrm{~A} / \mathrm{m}^{2}$, the homogeneous deformation [5] and the crystallization [6] at low temperatures induced by resonant electropulsing and the decrease in the dynamic Young's modulus in the frequency range between $10^{2} \mathrm{~Hz}$ and $10^{4} \mathrm{~Hz}$ [7]. The number of atoms in a collective motion responsible for such phenomena was estimated to the order of $10^{4}$ atoms $[3,4]$ which was attributed to the density and/or the chemical fluctuations existing in metallic glasses [8-10]. Recently, it was reported for several bulk metallic glasses (BMG) that ultrasound induced the rapid crystallization around the glass transition temperature, $T_{g}$, where enhancement of atomic diffusion by the stochastic resonance was claimed to take place [11-13]. The underlying mechanisms for these characteristic phenomena are not known yet, where one of the reasons is a lack of the experimental knowledge 
concerned. In the present work, focused is the dynamic Young's modulus in BMG and that in marginal metallic glasses (MMG), where the knowledge on the relationship between the free volume and the dynamic Young's modulus can be expected because the free volume contained is considerably smaller in BMG than in MMG.

\section{Experimental}

Amorphous (a-) ribbon specimens of $a-\mathrm{Zr}_{55} \mathrm{Cu}_{30} \mathrm{Al}_{10} \mathrm{Ni}_{5}$ (BMG), $a-\mathrm{Zr}_{50} \mathrm{Cu}_{50}(\mathrm{MMG})$ and $a-\mathrm{Cu}_{50} \mathrm{Ti}_{50}$ (MMG) were prepared by the melt spinning method in a high-purity $\mathrm{Ar}$ gas atmosphere. Four side surfaces of a ribbon specimen were mechanically polished into the rectangular shape and the thickness and width of the polished specimens were about $20 \mu \mathrm{m}$ and $0.7 \mathrm{~mm}$ respectively. The static Young's modulus, $E_{s}$, were measured by quasi-static tensile tests in the strain range below about $0.3 \%$, where specimens showed the linear elastic behavior. The dynamic Young's modulus, $E\left(\varepsilon_{t}, f\right)$, was measured as a function of the strain amplitude, $\varepsilon_{t}$, and the frequency, $f$, by means of the vibrating reed methods described in [7]. $E\left(\varepsilon_{t 0}, f\right)$ was measured as a function of the specimen length at $\varepsilon_{t 0}$ of $10^{-6}$ and $E\left(\varepsilon_{t}, f_{0}\right)$ was measured as a function of the vibrating amplitude at $f_{0}$ of $\sim 100 \mathrm{~Hz}$, respectively. A change in $E\left(\varepsilon_{t 0}, f_{0}\right)$ under PEC was measured as a function of the current density $i_{d}$ at $\varepsilon_{t 0}$ of $10^{-6}$ and $f_{0}$ between $\sim 10$ and $1000 \mathrm{~Hz}$, where the measurement setup was similar to that reported in [14].

\section{Results}

Figs. 1(a) to 1(c) show the Young's modulus data observed for $a-\mathrm{Zr}_{55} \mathrm{Cu}_{30} \mathrm{Al}_{10} \mathrm{Ni}_{5}$. For the quasi static tensile test (Fig. 1(a)), the linear elasticity was observed for $\varepsilon_{t}$ below $0.5 \%$, where $E_{s}$ of $97.5 \mathrm{GPa}$ was determined as the mean value of four as prepared specimens. As seen in Fig. 1(b), $E\left(\varepsilon_{t 0}, f\right)$ observed between $10 \mathrm{~Hz}$ and $10^{3} \mathrm{~Hz}$ are considerably lower than $E_{s}$ showing local minima, where the outline of $E\left(\varepsilon_{t 0}, f\right)$ is similar among the specimens but the amount of decrease in $E\left(\varepsilon_{t 0}, f\right)$ measured referred to $E_{s}$ was variable among specimens. In Fig. 1(c), $E\left(\varepsilon_{t 0}, f\right)$ and $E_{s}$ observed for the specimens annealed at $570 \mathrm{~K}, 700 \mathrm{~K}$ and $850 \mathrm{~K}$ for $0.5 \mathrm{~h}$ are shown. In the X-ray diffraction (XRD) measurements (not shown here), no crystallization was detected after annealing at $570 \mathrm{~K}$ and $700 \mathrm{~K}$ but the fractional volume of about $70 \%$ was crystallized after annealing at $850 \mathrm{~K}$, respectively. $E_{s}$ showed an increase with increasing annealing temperature. Referring to $E_{s}$, the $E\left(\varepsilon_{t 0}, f\right)$ data observed after annealing at $570 \mathrm{~K}$ and $700 \mathrm{~K}$ were similar to those found for the as prepared specimens. In contrast, the $E\left(\varepsilon_{t 0}, f\right)$ data observed after annealing at $850 \mathrm{~K}$ fell near $E_{s}$, indicating that the decrease in $E\left(\varepsilon_{t 0}, f\right)$ is characteristic of metallic glasses. Figs. 2(a) and (b) show the $E\left(\varepsilon_{t 0}, f\right)$ data observed for $a-\mathrm{Zr}_{50} \mathrm{Cu}_{50}$ and $a-\mathrm{Cu}_{50} \mathrm{Ti}_{50}$, respectively. Both the $E\left(\varepsilon_{t 0}, f\right)$ data are similar to those for $a-\mathrm{Zr}_{55} \mathrm{Cu}_{30} \mathrm{Al}_{10} \mathrm{Ni}_{5}$ shown in Fig. 1(b).

Fig. 3 shows examples for the $\left(f / f_{0}\right)^{2} v$ s. $\varepsilon_{t}$ data observed for $a-\mathrm{Zr}_{55} \mathrm{Cu}_{30} \mathrm{Al}_{10} \mathrm{Ni}_{5}, a-\mathrm{Zr}_{50} \mathrm{Cu}_{50}$ and $a-\mathrm{Cu}_{50} \mathrm{Ti}_{50}$, where $E\left(\varepsilon_{t}, f_{0}\right) / E\left(\varepsilon_{t 0}, f_{0}\right) \sim\left(f / f_{0}\right)^{2}$. With increasing $\varepsilon_{t},\left(f / f_{0}\right)^{2}$ showed an increase followed by saturation. The out line of the $\left(f / f_{0}\right)^{2}$ vs. $\varepsilon_{t}$ data observed for $a-Z_{5} r_{55} \mathrm{Cu}_{30} \mathrm{Al}_{10} \mathrm{Ni}_{5}$, $a-\mathrm{Zr}_{50} \mathrm{Cu}_{50}$ and $a-\mathrm{Cu}_{50} \mathrm{Ti}_{50}$ were very similar to that already reported [15] except that the amounts of the increases in $\left(f / f_{0}\right)^{2}$ observed in the present $a-Z_{50} \mathrm{Cu}_{50}$ and $a$ - $\mathrm{Cu}_{50} \mathrm{Ti}_{50}$ specimens were about $60 \%$ of those in the $a-\mathrm{Zr}_{50} \mathrm{Cu}_{50}$ and $a-\mathrm{Cu}_{50} \mathrm{Ti}_{50}$ specimens used in [15]. A change in $E\left(\varepsilon_{t 0}, f_{0}\right)$ under PEC with $i_{d} \sim 10^{7} \mathrm{~A} / \mathrm{m}^{2}$ was measured in a He gas atmosphere of about $0.1 \mathrm{~atm}$ in order to minimize an increase in the specimen temperature due to joule heating [14]. Fig. 4 shows an example of a change in the temperature along the specimen long 
axis, $\Delta T_{x}$, observed during resonant vibrations of a reed specimen of $a-\mathrm{Zr}_{50} \mathrm{Cu}_{50}$ under PEC. The observed $\Delta T_{x} v$ s. distance, $x$, data reflect the experimental setup that the specimen was clamped at $x=0$ and thermally anchored at the specimen top of $x=L$ by a thin copper lead ribbon. The dashed line denotes the relative change in strain, $\varepsilon_{x} / \varepsilon_{0}$, estimated from the vibration shape [16]. Fig. 5(a) shows the observed change in $f$ as a function of $i_{d}$ and the estimated change in $f$ due to joule heating which was evaluated from using the $\Delta T_{X}$ data, $\varepsilon_{X} / \varepsilon_{0}$ and the temperature change in $f$ measured separately without PEC. The intrinsic change in $f$, $\Delta f_{\mathrm{PEC}}$, due to PEC was determined as shown in Fig. 5(a). Fig. 5(b) shows $\Delta f_{P E C} / f_{0}$ as a function of $i_{d}$ and the $\Delta f / f_{0} v s$. $\varepsilon_{t}$ deduced from the $\left(f / f_{0}\right)^{2} v s . \varepsilon_{t}$ data shown in Fig. 3. They were compared by assuming the scaling relationship, $\varepsilon_{t}=\alpha i_{d}$, between $i_{d}$ and $\varepsilon_{t}$ with a proportional constant, $\alpha$. The scaling assumed that the electromigration force acting to an atom was the same to the elastic force acting to an atom under stress, giving the relationship,

$$
Z^{*}=\alpha S E / e \rho_{\mathrm{R}}
$$

where $Z^{*}, S, e$ and $\rho_{R}$ denote the effective charge number, a dimensional cross-section of an atom, the elementary charge and the specific resistivity of the a-alloy, respectively (see $[14,17]$ for details). Figs. 6(a) and (b) show the $Z^{*} v s$. $f$ data found for $a-Z_{50} \mathrm{Cu}_{50}$ together with that reported [17] and for $a-\mathrm{Zr}_{55} \mathrm{Cu}_{30} \mathrm{Al}_{10} \mathrm{Ni}_{5}$, respectively. For both $a-\mathrm{Zr}_{50} \mathrm{Cu}_{50}$ and $a-\mathrm{Zr}_{55} \mathrm{Cu}_{30} \mathrm{Al}_{10} \mathrm{Ni}_{5}, Z^{*}$ was in the order of $10^{5}$ in the frequency range between $50 \mathrm{~Hz}$ and 1000 $\mathrm{Hz}$ and showed a decrease with increasing $f$.

\section{Discussion}

Fig. 7 shows the schematic drawing for the strain and frequency dependence of the Young's modulus of metallic glasses reported in $[7,14]$, where $E_{s}, E\left(\varepsilon_{t 0}, f\right)$ and $E\left(\varepsilon_{t}, f_{0}\right)$ are depicted by the line $A B$, the curve ACD and the curve $C E$, respectively. Computer simulation works on metallic glass $[18,19]$ have shown that the amorphous structure is composed of the relatively lower dense region (RLDR) and the relatively higher dense region (RHDR). It is suggested that the reversible shear deformation of small deformable units in the RLDR is responsible for the much lower $E_{s}$ in the amorphous state compared with that in the crystalline state [19]. For $a-\mathrm{Zr}_{55} \mathrm{Cu}_{30} \mathrm{Al}_{10} \mathrm{Ni}_{5}$, the constituent anelastic strain, $\varepsilon_{a}$, in $\varepsilon_{t}$ for the quasi static tensile tests was estimated as about 0.25 in the ratio $\varepsilon_{a} / \varepsilon_{t}$ from the $E_{s}$ data shown in Fig. 1(c). For the decreased $E\left(\varepsilon_{t 0}, f\right)$ observed between $10 \mathrm{~Hz}$ and $10^{3} \mathrm{~Hz}$ shown in Fig. 1(b), $\varepsilon_{a} / \varepsilon_{t}$ estimated was about 0.4 , indicating a strong increase in $\varepsilon_{a}$. In order to explain such strong increase in $\varepsilon_{a}$, the resonant collective motion of the RHDR embedded in the RLDR will be discussed below.

For the forced vibration of resonant systems with the mass, $m$, the dependence of the displacement amplitude, $x_{0}$, on the angular frequency, $\omega$, can be given by

$$
x_{0}^{2}=\left(F_{0} / m\right)^{2} /\left[\left(\omega^{2}-\omega_{r}^{2}\right)^{2}+\omega_{r}^{4} \tan ^{2} \phi\right],
$$

where $F_{0}$ is the strength of a periodic applied force, $\omega_{r}$ is the resonant angular frequency and $\phi$ is the loss angle [16]. Then, we assume that $\varepsilon_{a}$, is explained by,

$$
\varepsilon_{a}=\beta /\left[\left(\omega^{2}-\omega_{r}^{2}\right)^{2}+\omega_{r}^{4} \tan ^{2} \phi\right]^{1 / 2},
$$

and $E\left(\varepsilon_{t 0}, f\right)$ is given by, 


$$
E\left(\varepsilon_{t 0}, f\right)=E_{s}\left[\varepsilon_{0} /\left(\varepsilon_{0}+\varepsilon_{a}\right)\right]
$$

where $\varepsilon_{0}$ is the elastic strain and $\beta$ is a proportional constant. For the resonant collective motion of RHDR, $\tan \phi$ may be considerably large because the RHDR is embedded in the RLDR. For such case, the dependence of $\varepsilon_{a}$ on $\omega$ is not strongly modified by a change in $\tan \phi$. Dashed curves shown in Figs. 1(b), 2(a) and 2(b) were the theoretical values of $E\left(\varepsilon_{t 0}\right.$, $f$ ) fitted to the observed data, where $\tan ^{2} \phi$ was assumed to be 0.5 and the $\omega_{r}$ data used were those found in the electropulsing-induced crystallization on $a-\mathrm{Cu}_{50} \mathrm{Ti}_{50}$ [6] and $a-\mathrm{Zr}_{50} \mathrm{Cu}_{50}$ and $a-\mathrm{Zr}_{55} \mathrm{Cu}_{30} \mathrm{Al}_{10} \mathrm{Ni}_{5}$ (not shown here). For $a-\mathrm{Cu}_{50} \mathrm{Ti}_{50}$ shown in Fig. 2(b), the theoretical values of $E\left(\varepsilon_{t 0}, f\right)$ explained well the observed data. For $a-\mathrm{Zr}_{50} \mathrm{Cu}_{50}$ and $a-\mathrm{Zr}_{55} \mathrm{Cu}_{30} \mathrm{Al}_{10} \mathrm{Ni}_{5}$, although the $\omega_{r}$ data are limited at present, but the theoretical values of $E\left(\varepsilon_{t 0}, f\right)$ appeared to explain well the observed data too.

For $E\left(\varepsilon_{t}, f_{0}\right)$ shown in Fig. 3 and the curve CE in Fig. 7, the saturation in the reversible shear deformation of small deformable units [20] can be explained them. Then, one may expect the similar change in $E\left(\varepsilon_{t 0}, f_{0}\right)$ at $\varepsilon_{t 0}$.of $10^{-6}$ when the concentration of the electromigration force takes place through a collective motion of many atoms. The net increase in $E\left(\varepsilon_{t 0}, f_{0}\right)$ under PEC as seen in Fig. 5(a) is indicative of the concentration of the electromigration force, where $Z^{*}$ is indicative of the number of atoms associated with the collective motion. As shown in Figs. 6(a) and 6(b), for both $a-\mathrm{Zr}_{50} \mathrm{Cu}_{50}$ and $a-\mathrm{Zr}_{55} \mathrm{Cu}_{30} \mathrm{Al}_{10} \mathrm{Ni}_{5}$, $Z^{*}$ was in the order of $10^{5}$ and showed a decrease with increasing $f$. It is noted that the present value of $Z^{*}$ is larger by four to five digits than the electromigration charge number of a single atom in a concentrated alloy [21]. The decrease in $Z^{*}$ with increasing $f$ may indicates that the number of atoms in the RHDR associated with the resonant collective motions decrease with increasing resonant frequency.

It is known that the free volume existing in BMG is considerably smaller than that in MMG. It is not for the free volume but the crystallization volume reported is $0.8 \%$ for $a-\mathrm{Cu}_{50} \mathrm{Ti}_{50}$ [22], $2.1 \%$ for $a-\mathrm{Zr}_{50} \mathrm{Cu}_{50}$ [23] and $0.4 \%$ for $a-\mathrm{Zr}_{55} \mathrm{Cu}_{30} \mathrm{Al}_{10} \mathrm{Ni}_{5}$ [24], respectively. On the other hand, the magnitudes of various anelastic responses for $E\left(\varepsilon_{t 0}, f\right)$ and $E\left(\varepsilon_{t}, f_{0}\right)$ were very similar among these metallic glasses, indicating that the correlation between the present characteristic anelastic phenomena and the free volume in metallic glasses is not too strong. Further speculation is premature at present, however, the present work demonstrated characteristics of collective motions of many atoms in metallic glasses.

\section{Conclusion}

The elastic properties associated with the collective motion of many atoms in $a-\mathrm{Cu}_{50} \mathrm{Ti}_{50}$ (MMG), $a-\mathrm{Zr}_{50} \mathrm{Cu}_{50}$ (MMG) and $a-\mathrm{Zr}_{55} \mathrm{Cu}_{30} \mathrm{Al}_{10} \mathrm{Ni}_{5}$ (BMG) were investigated. The magnitudes of the anelastic responses for $E\left(\varepsilon_{t}, f\right)$ and $E\left(\varepsilon_{t}, f_{0}\right)$ and the effective charge number $Z^{*}$ for the effect of PEC on $E\left(\varepsilon_{t 0}, f_{0}\right)$ were found to be similar among these metallic glasses indicating that the correlation between the present characteristic anelastic phenomena and the free volume in metallic glasses is not too strong. The decrease in $Z^{*}$ with increasing $f$ was found, indicating that the number of atoms in the RHDR associated with the resonant collective motions decrease with increasing resonant frequency. The underlying mechanism was discussed in the light of excitation of the resonant collective motions in metallic glasses. 


\section{Acknowledgement}

This work is partly supported by a Grant in Aid for Scientific Research and the $21^{\text {st }}$ Century Center of Excellence Program from the Ministry of Education, Culture, Sports, Science and Technology, Japan.

\section{References}

[1] H. Mizubayashi and S. Okuda, Phys. Rev. B 40 (1989) 8057.

[2] Z.H. Lai, H. Conrad, Y.S. Chao, S.Q. Wang and J. Sun, Scripta Metall. 23 (1989) 305.

[3] H. Mizubayashi and R. Takemoto, J. Alloys and Compd. 211/212 (1994) 340.

[4] R. Takemoto and H. Mizubayashi, Acta Metall. Mater. 43 (1995) 1495.

[5] H. Mizubayashi and T. Okamoto, Mater. Sci. Forum, 304-306 (1999) 355.

[6] H. Mizubayashi, N. Kameyama, T. Hao and H. Tanimoto, Phys. Rev. B 64 (2001) 054201.

[7] H. Mizubayashi, T. Okamoto, K. Koyama and M. Horiuchi, Acta Mater. 46 (1998) 1257.

[8] K. Maeda, S. Takeuchi, J. Phys. F : Met. Pys. 12 (1982) 2767.

[9] J.-B. Suck, J. Non-cryst. Solids 293-295 (2001) 370

[10] A.S. Bakai, V.V. Kul'ko, I.M.Mikhailovskij, V.B. Rabukhin, O.A. Velikodnaya, J. Non-cryst. Solids.182 (1995) 315.

[11] T. Ichitsubo, S. Kai, H. Ogi, M. Hirao and K. Tanaka, Scripta Mater. 49 (2003) 267.

[12] T. Ichitsubo, E. Matsubara, S. Kai, and M. Hirao, Acta Mater. 52 (2004) 423.

[13] T. Ichitsubo, E. Matsubara, K. Anazawa, N. Nishiyama, S. Kai, and M. Hirao, Mater. Trans. JIM 45 (2004) 1189.

[14] H. Mizubayashi, T. Usui, H. Tanimoto, Mater. Sci. Engng. A 370 (2004) 260.

[15] H. Mizubayashi, T. Usui, H. Tanimoto, J. Non-cryst. Solids 312-314 (2002) 542.

[16] A.S. Nowick and B.S. Berry, Anelastic Relaxation in Crystalline Solids (Academic Press, New York, 1972) p. 15 and p. 626.

[17] R. Takemoto, M. Nagata and H. Mizubayashi, Acta Metall. Mater. 44 (1996) 2787.

[18] D. Weaire, M.F. Ashby, J. Logan and M.J. Weins, Acta Metall. 19 (1971) 779.

[19] S. Takeuchi and K. Maeda, Key Engineering Materials 13/15 (1987) 749.

[20] Y. Suzuki, J. Haimovich, and T. Egami, Phys. Rev. B 35 (1987) 2162.

[21] H.B. Huntington, Diffusion in Solids, ed. A.S. Nowic and J.J.Burton (Academic Press, New York, 1975), p.303.

[22] H. Mizubayashi, S. Hoshina and S. Okuda, J. Non-Crystalline Solids 117/118 (1990) 203.

[23] H. Mizubayashi, M. Kaida, S. Otsuka and S. Okuda, Acta Mater. 42 (1994) 2099.

[24] A. Inoue, Acta Mater. 48 (2000) 279. 

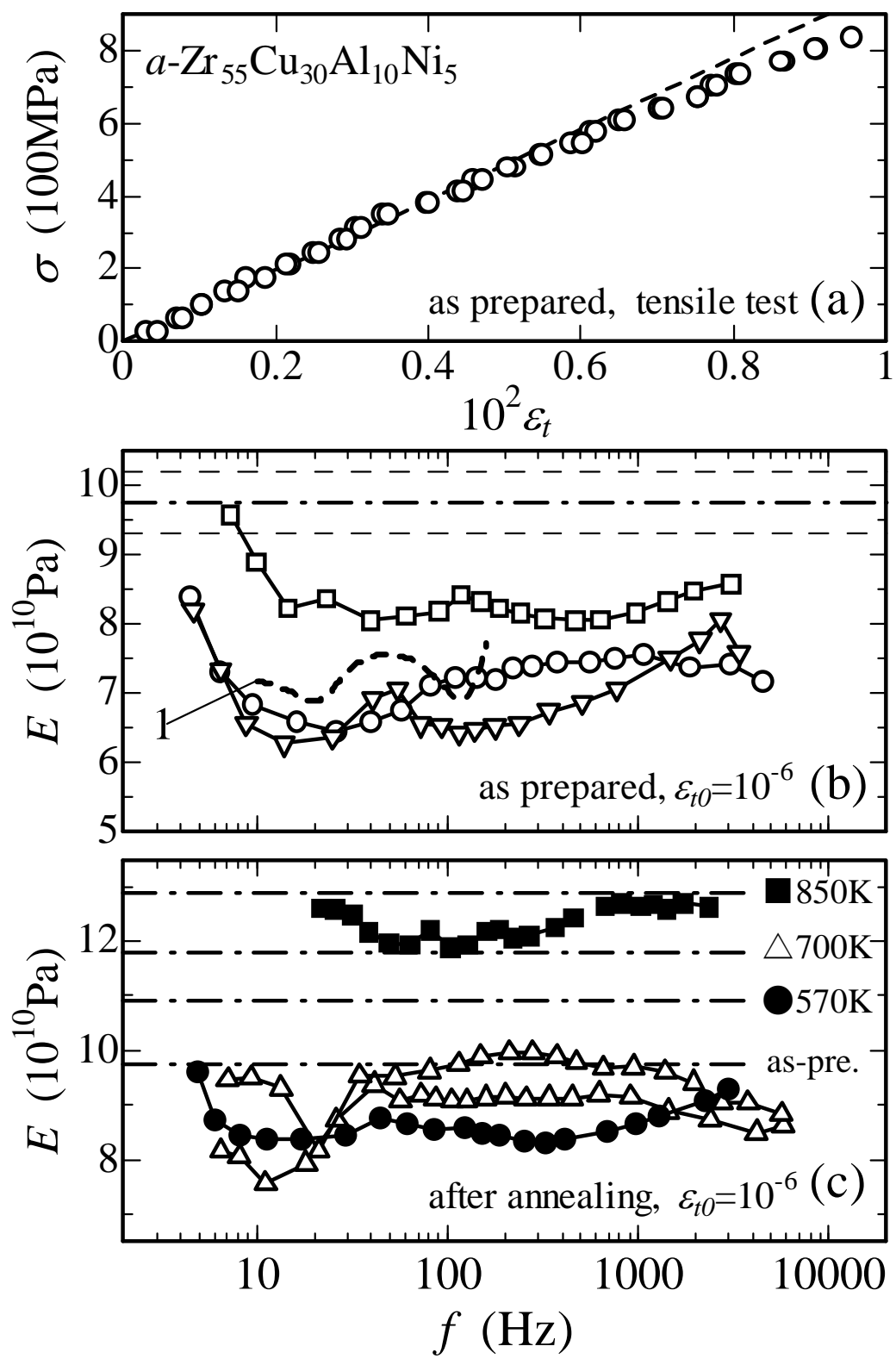

Fig. 1.

The Young's modulus data observed for $a-\mathrm{Zr}_{55} \mathrm{Cu}_{30} \mathrm{Al}_{10} \mathrm{Ni}_{5}$. (a) An example of the quasi static tensile test for an as prepared specimen, where the dashed line denotes the linear elasticity with $E_{s}$ of $97.5 \mathrm{GPa}$ which was the mean value of four specimens (not shown here). (b) Examples of $E\left(\varepsilon_{t 0}, f\right)$ observed with $\varepsilon_{t 0}=10^{-6}$ for three as-prepared specimens (symbols). The dash and dotted line denotes $E_{s}$ mentioned above and two dashed lines denote the range in which the $E_{s}$ data were found. (c) Similar to (b) but here shown are the $E\left(\varepsilon_{t 0}, f\right)$ data $(\mathbf{O})$ and $E_{s}$ observed for the specimen after annealing at $570 \mathrm{~K}$ for $0.5 \mathrm{~h}$, the $E\left(\varepsilon_{t 0}, f\right)$ data $(\triangle)$ and $E_{s}$ observed for the two specimens after annealing at $700 \mathrm{~K}$ for $0.5 \mathrm{~h}$ and the $E\left(\varepsilon_{t 0}, f\right)$ data ( $\boldsymbol{\square})$ and $E_{s}$ observed for the specimen after annealing at $850 \mathrm{~K}$ for $0.5 \mathrm{~h}$. See text for the dashed curve 1 in (b). 

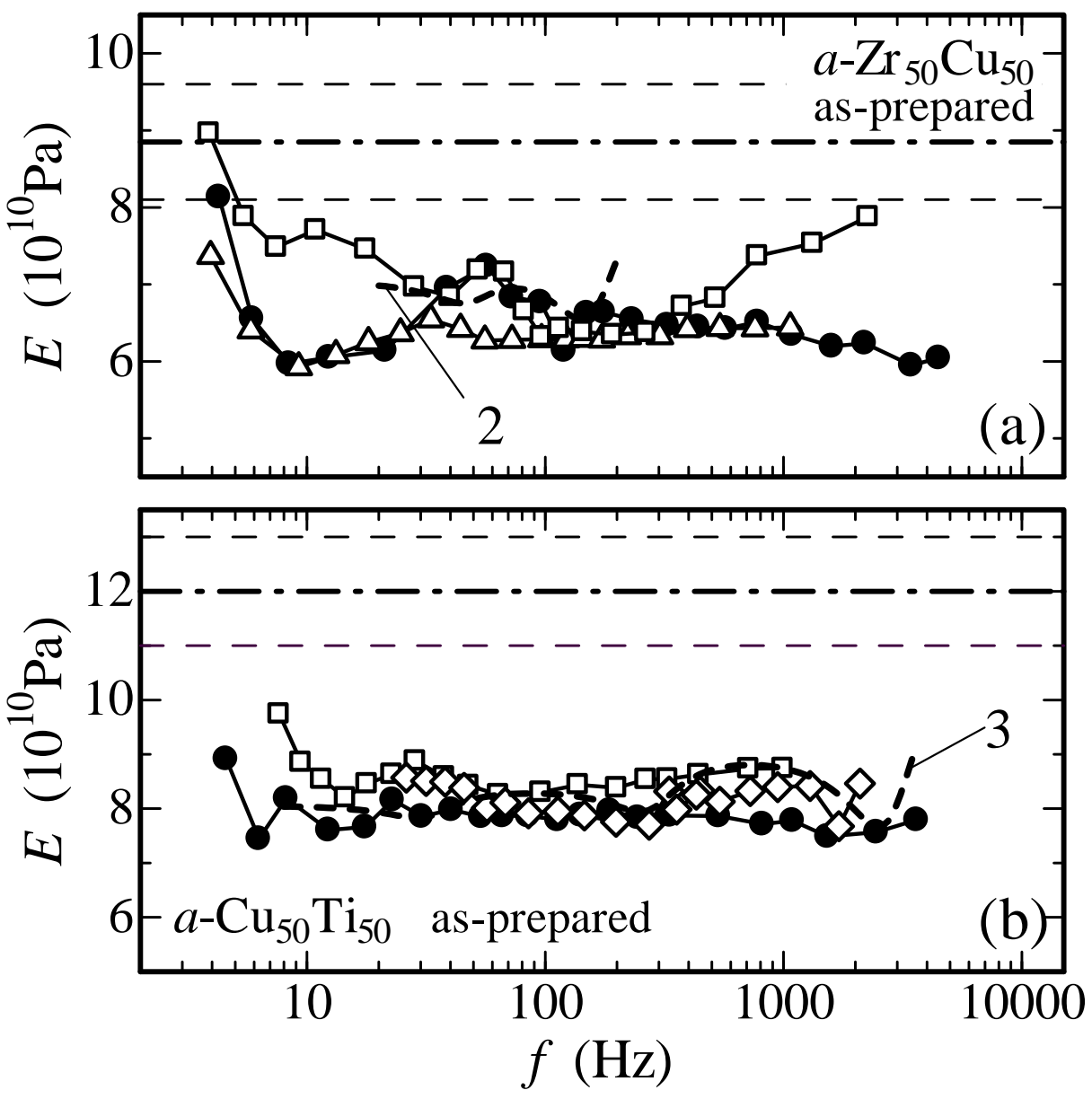

Fig. 2.

Similar to Fig. 1(b) but here the $E\left(\varepsilon_{t 0}, f\right)$ data observed for (a) three as prepared specimens of $a-\mathrm{Zr}_{50} \mathrm{Cu}_{50}$ and (b) three as prepared specimens of $a-\mathrm{Cu}_{50} \mathrm{Ti}_{50}$. See text for the dashed curve 2 and 3. 


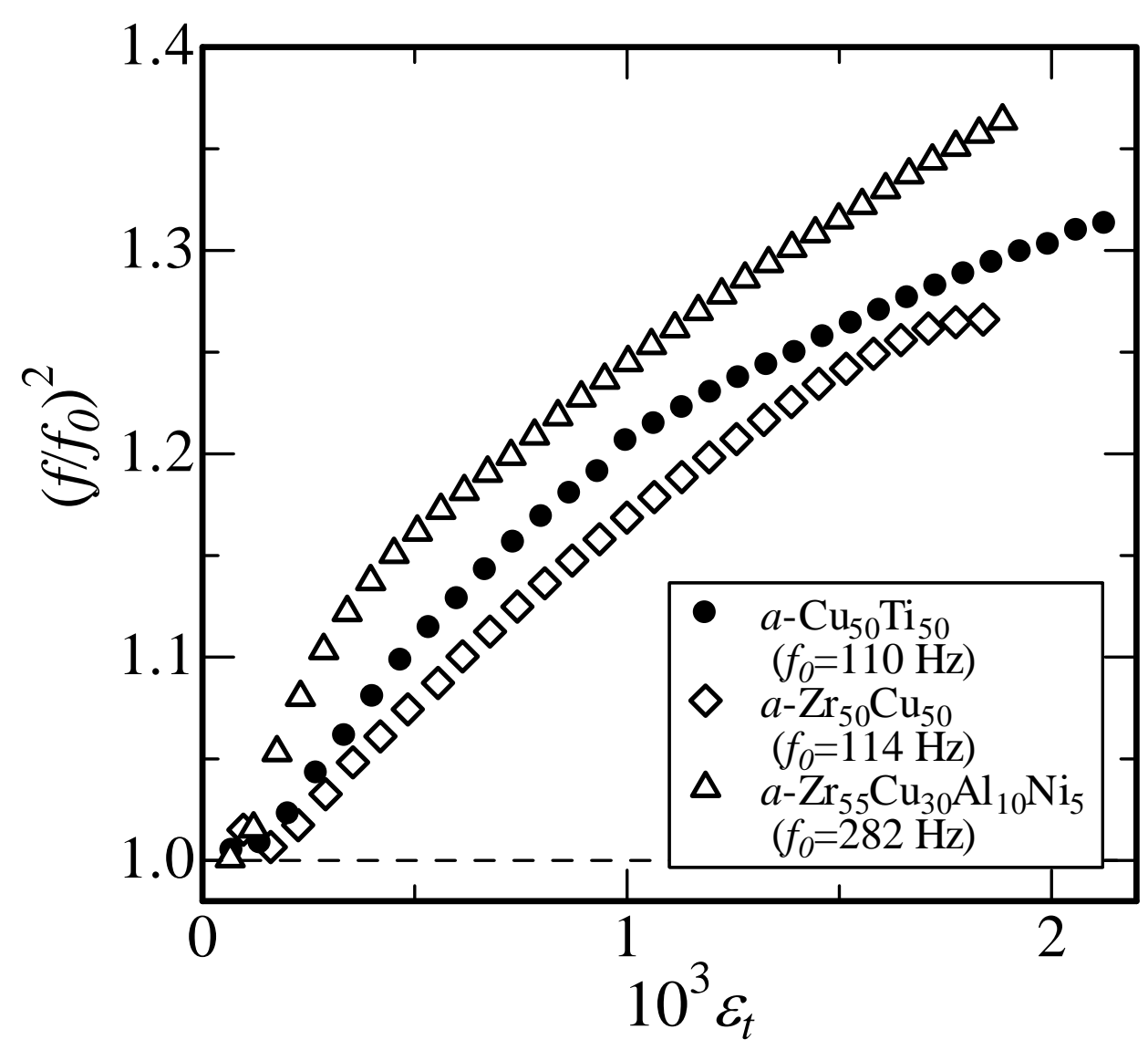

Fig. 3.

Examples for the $\left(f / f_{0}\right)^{2}$ vs. $\varepsilon_{t}$ data observed for $a-\mathrm{Zr}_{55} \mathrm{Cu}_{30} \mathrm{Al}_{10} \mathrm{Ni}_{5}$, $\mathrm{a}-\mathrm{Zr}_{50} \mathrm{Cu}_{50}$ and $\mathrm{a}-\mathrm{Cu}_{50} \mathrm{Ti}_{50}$. 


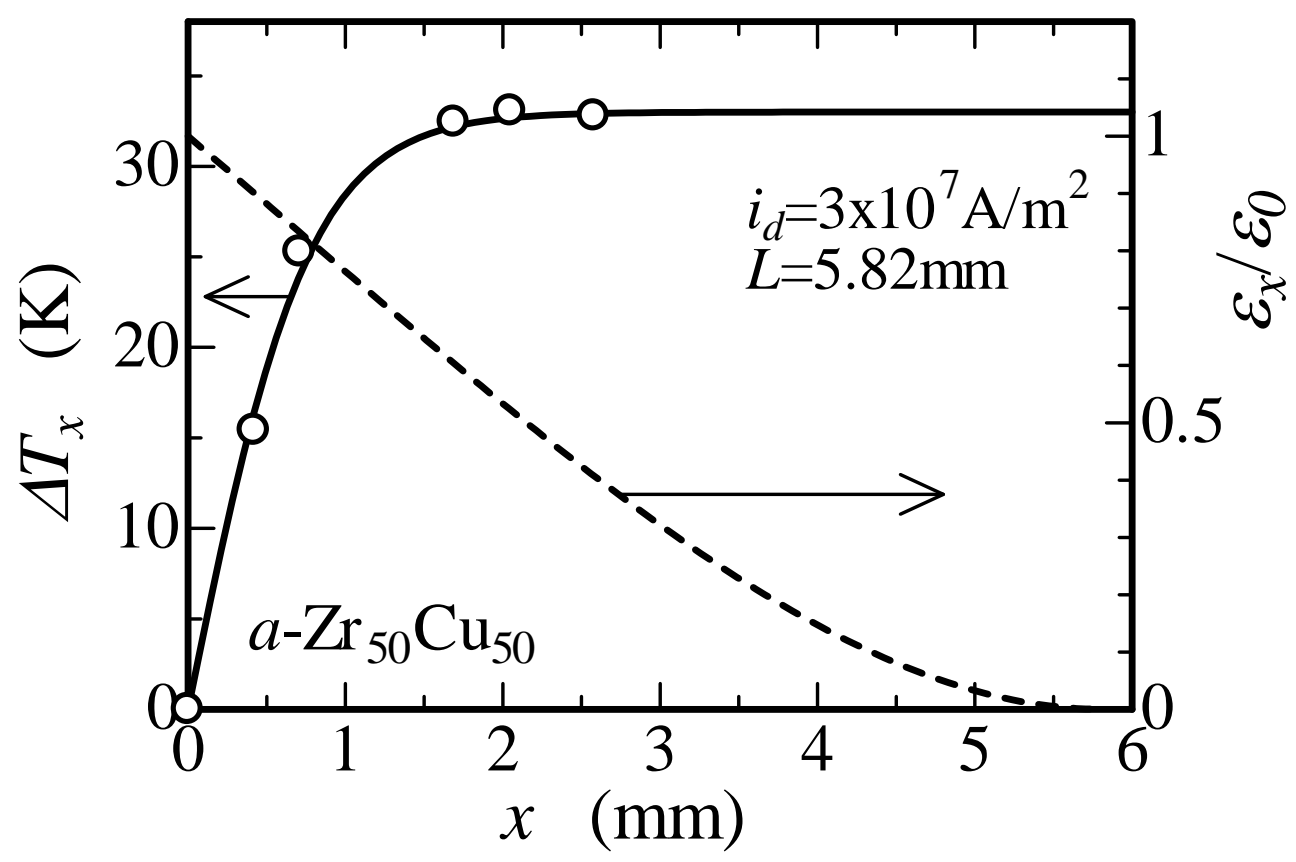

Fig. 4.

An example of a change in the temperature along the specimen long axis, $\Delta T_{x}$, during PEC with $i_{d}=3.0 \times 10^{7} \mathrm{~A} / \mathrm{m}^{2}$ observed for an $\mathrm{a}-\mathrm{Zr}_{50} \mathrm{Cu}_{50}$ specimen $(\bigcirc)$. The dashed line denotes the relative change in strain, $\varepsilon_{X} / \varepsilon_{0}$, estimated from the vibration shape [16]. 


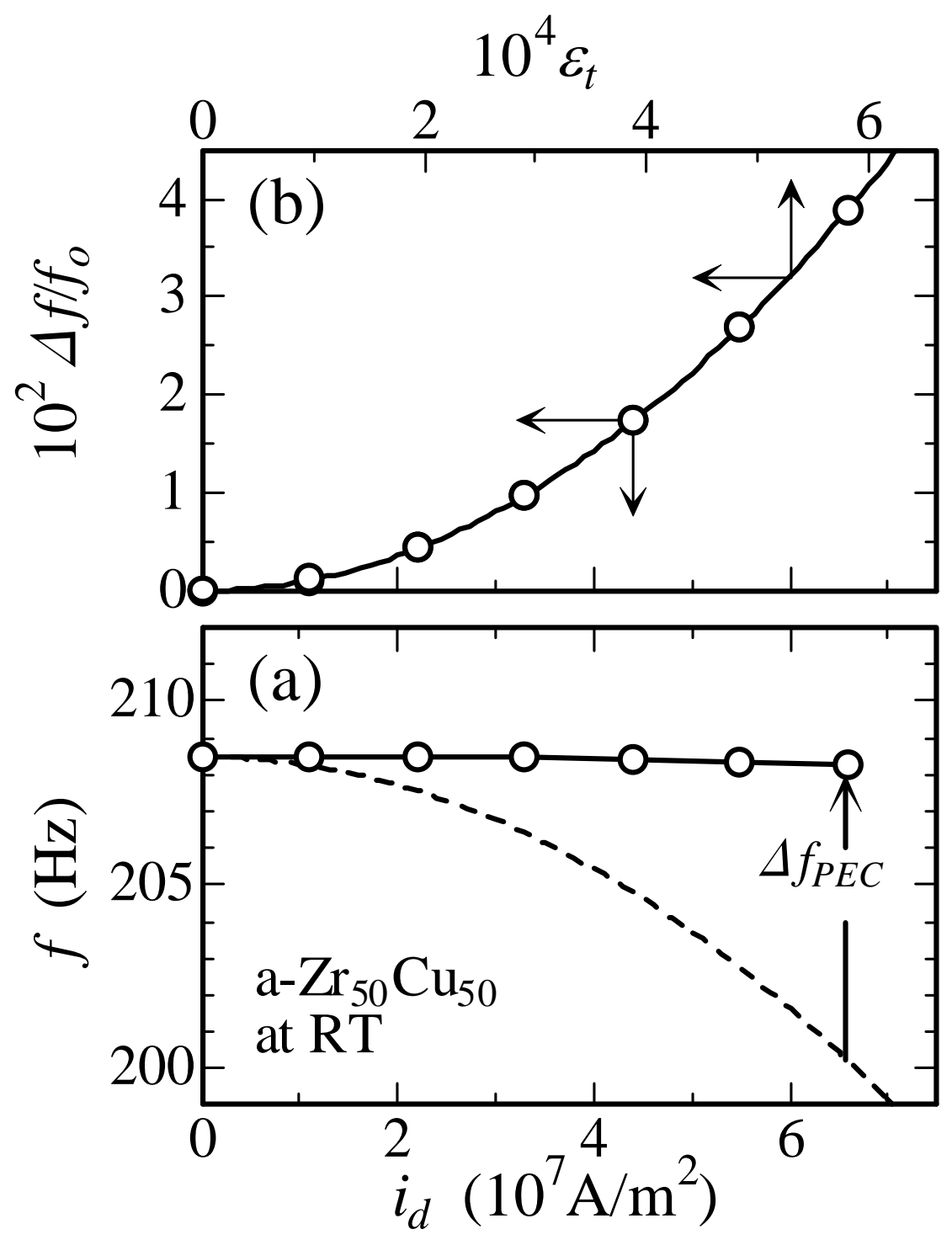

Fig. 5.

An example of a change in $E\left(\varepsilon_{t 0}, f_{0}\right)$ under PEC observed for $a-\mathrm{Zr}_{50} \mathrm{Cu}_{50}$. (a) The $f v s . i_{d}$ data $(\bigcirc)$ and the change in $f$ due to the joule heating (the dashed curve), where the net effect of PEC on $f$, $\Delta f_{P E C}$, was determined as shown in the figure. (b) The $\Delta f_{P E C} / f_{0} v s . i_{d}$ data $(\bigcirc)$ was compared with the $f / f_{0} v s$. $\varepsilon_{t}$ data shown in Fig. 3 (the solid curve) after scaling them. See text for details. 

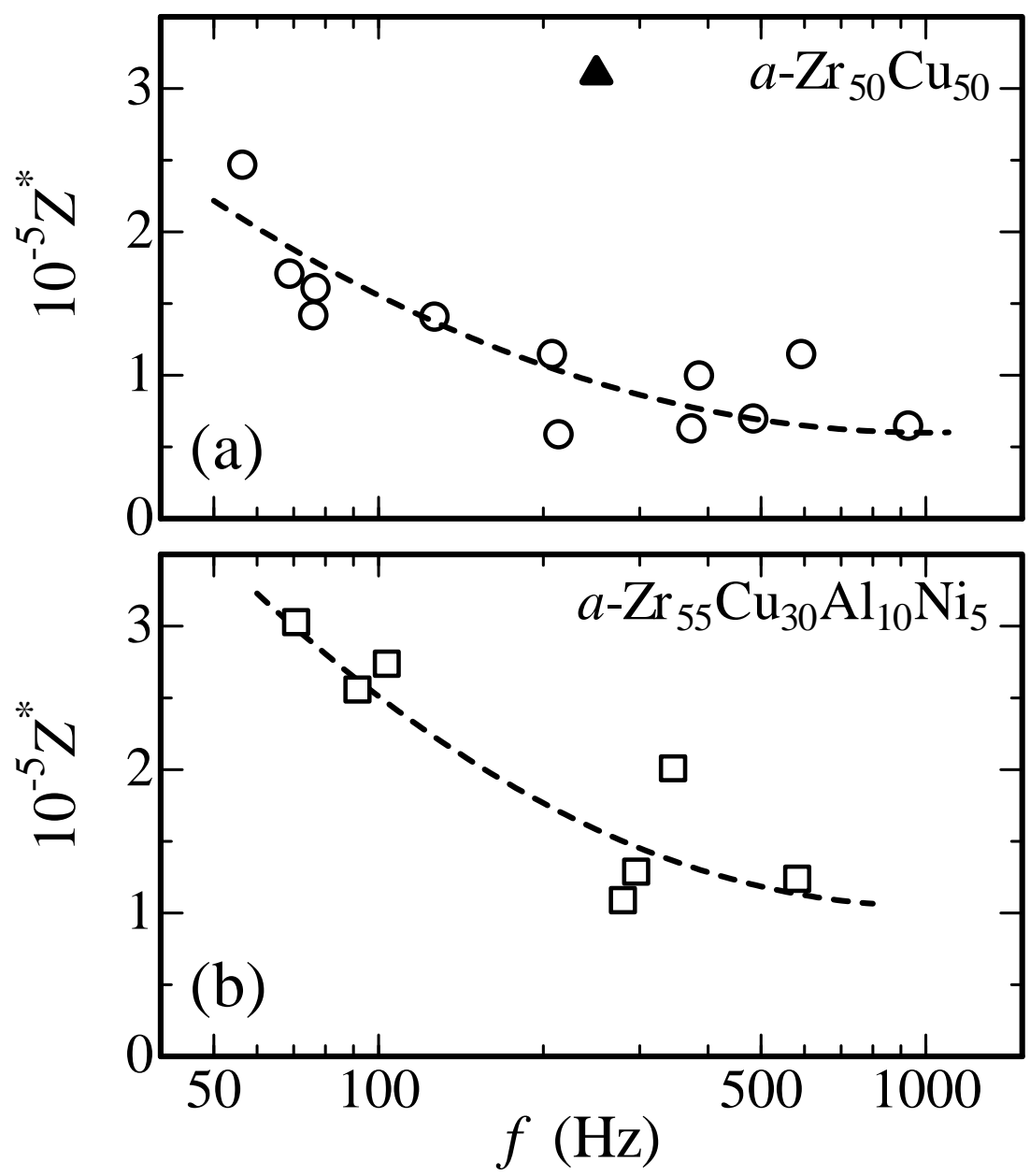

Fig. 6.

The $Z^{*} v s$. $f$ data found for (a) $a-Z_{50} \mathrm{Cu}_{50}(\bigcirc)$ together with that reported ( $\boldsymbol{\Delta})$ [17] and (b) $a-\mathrm{Zr}_{55} \mathrm{Cu}_{30} \mathrm{Al}_{10} \mathrm{Ni}_{5}(\square)$. Dashed curves are drawn to guide eyes. 


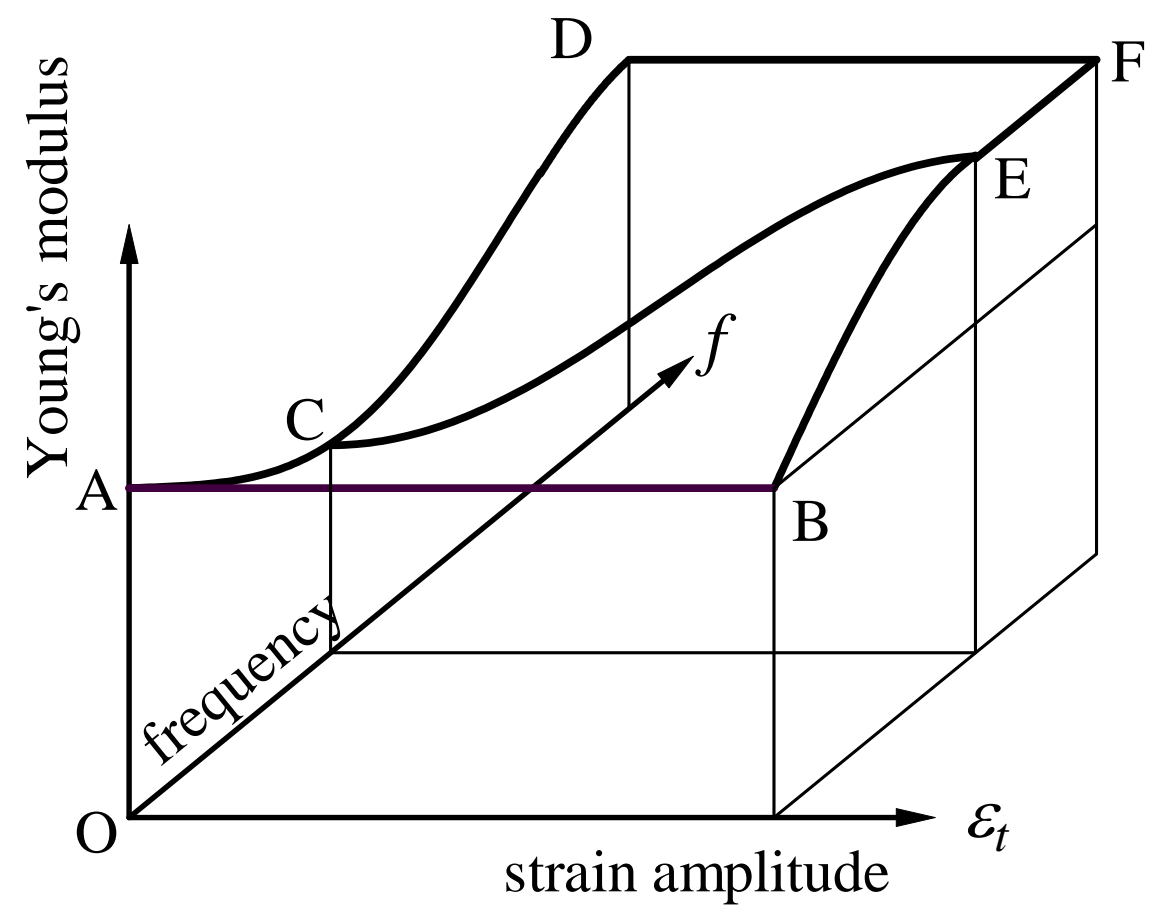

Fig. 7.

The schematic drawing for the strain and frequency dependence of the Young's modulus of metallic glasses $[7,14]$. 